OPEN ACCESS

Edited by:

Federica Cipriani,

San Raffaele Scientific Institute

(IRCCS), Italy

Reviewed by:

Marco Massani,

ULSS2 Marca Trevigiana, Italy

Irene Scalera,

University of Bari Medical School, Italy

*Correspondence: Riad Haddad dr.riad.haddad@gmail.com

Specialty section: This article was submitted to

Surgical Oncology,

a section of the journal

Frontiers in Surgery

Received: 23 July 2021 Accepted: 31 October 2021 Published: 25 November 2021

Citation:

Abu-Zaydeh O, Sawaied M, Berger Y, Mahamid A, Goldberg N, Sadot E and

Haddad R (2021) Hand-Assisted

Laparoscopic Surgery Is Superior to Open Liver Resection for Colorectal

Liver Metastases in the

Posterosuperior Segments.

Front. Surg. 8:746427.

doi: 10.3389/fsurg.2021.746427

\section{Hand-Assisted Laparoscopic Surgery Is Superior to Open Liver Resection for Colorectal Liver Metastases in the Posterosuperior Segments}

\author{
Omar Abu-Zaydeh ${ }^{1}$, Muneer Sawaied ${ }^{1}$, Yael Berger ${ }^{2,3}$, Ahmad Mahamid $^{1,4}$, \\ Natalia Goldberg ${ }^{4,5}$, Eran Sadot ${ }^{2,3}$ and Riad Haddad ${ }^{1,4 *}$
}

${ }^{1}$ Department of Surgery, Carmel Medical Center, Haifa, Israel, ${ }^{2}$ Department of Surgery, Rabin Medical Center, Petah Tikva, Israel, ${ }^{3}$ Sackler School of Medicine, Tel Aviv University, Tel Aviv, Israel, ${ }^{4}$ The Ruth and Bruce Rappaport Faculty of Medicine, Technion, Israel Institute of Technology, Haifa, Israel, ${ }^{5}$ Department of Radiology, Carmel Medical Center, Haifa, Israel

Introduction: Laparoscopic liver resections (LLR) of colorectal metastasis located in posterosuperior segments (1, 4A, 7 and 8 ) are challenging and highly demanding. The aim of our study is to determine the safety and feasibility of hand-assisted laparoscopic surgery (HALS) in the resections of the posterosuperior lesions and to compare the peri-operative, short-term and long-term outcomes with the open liver resection (OLR) approach.

Methods and Results: A retrospective study of patients who underwent either HALS or OLR for metastatic colorectal cancer ( $\mathrm{mCRC}$ ) located in the posterosuperior segments of the liver between 2008 and 2018 in two university affiliated medical centers.

Results: A total of 187 patients were identified, of whom 78 underwent HALS and 109 underwent OLR. There was no difference between the HALS and OLR with regard to preoperative factors (age, primary CRC tumor location, number and anatomical distribution of liver metastasis, pre-operative neo-adjuvant treatment, operative time, blood transfusion rate, and resection margins positivity). On the other hand, HALS compared to OLR had a significantly shorter mean hospital stay (4 vs. 6 days; $P=0.003$ ), and a lower total complications rate ( $25 \mathrm{vs.} 47 \% P=0.006$ ). Both groups had no 30 -day mortality. Also, patients who underwent HALS vs. OLR had similar liver metastases recurrence (55 vs. $51 \% . P=0.65$ ) and 5 -year survival (47 vs. $45 \% . P=0.72$ ).

Conclusions: HALS for mCRC located in posterosuperior liver segments is safe and feasible and it is a preferable approach due to its lower complication rate and shorter hospital stay while not compromising survival and disease recurrence.

Keywords: metastatic colon cancer (mCRC), hand-assisted laparoscopic surgery (HALS), laparoscopic liver resection (LLR), posterosuperior segments, open liver resection (OLR) 


\section{INTRODUCTION}

Minimally invasive surgery (MIS) has revolutionized many procedures in different surgical fields over the past three decades. However, the adoption of minimally invasive liver resection has been slow compared with the rate at which MIS approaches have been incorporated into luminal and other solid organ procedures (1-3). This slow adoption has persisted despite expanding indications and increasing experience in high volume centers (4).

Based on international data, primary liver cancer is the most common indication for laparoscopic liver resection (LLR), whereas metastatic disease may predominate as an indication in North America and Europe $(5,6)$. Of note, LLR is associated with a decrease in perioperative bleeding, faster mobilization, shorter hospital stays, and less morbidity, as well as being cost-effective (7-9). Furthermore, concerns on compromised short- and longterm oncological outcomes in LLR have been refuted by various studies (9-12).

For resection of colorectal liver metastases (CRLM), studies have shown that LLR results in superior perioperative outcomes and similar oncological outcomes (recurrence-free and overall survival) in selected patients compared to open liver resection (OLR) (9-12).

The Louisville consensus conference recommends laparoscopic liver resection for patients with a solitary lesion, $5 \mathrm{~cm}$ or less, located in the peripheral liver segments (13). However, in the Southampton guidelines (14) and after accumulated experience in laparoscopic liver surgery for colorectal liver metastases, the warnings and limitations were only for formal laparoscopic hemi-hepatectomy and for lesions in the postero-superior segments. These lesions (in segments 1, 4a, 7, and 8) have been considered especially challenging because of the limited surgical view and restricted handling of laparoscopic instruments $(15,16)$. However, recent progress in operative techniques, including the introduction of the transthoracic port placement, has reduced the difficulty of LLR for tumors in the posterosuperior liver (17).

Hand-assisted laparoscopic surgery (HALS) is defined as the placement of a hand port during laparoscopy. The main advantages of HALS are the possibility to control intraoperative bleeding via manual compression and the use of tactile sensation, to detect deeper intraparenchymal lesions, and provide better exposure of difficult tumor locations $(13,14,18)$.

To date, there is no published comparison of the surgical and long-term results of HALS vs. OLR for CRLM in the postero-superior segments. The aim of this study was therefore to compare the perioperative and long-term outcomes of LLR (HALS) and OLR for CRLM in the postero-superior segments.

\section{MATERIALS AND METHODS}

All consecutive patients who underwent either HALS or open resections with curative intent for CRLM located in posteriorsuperior liver segments (segments1, 4a, 7, and 8 ) between January 2008 and December 2018 were identified from prospectively maintained surgical databases at the Carmel and Rabin medical centers. Patients' data was collected by reviewing these electronic databases of both centers after receiving approval from their institutional review boards. Clinical data including demographic, perioperative and intraoperative variables, in addition to shortand long-term outcomes were collected retrospectively.

The indications for liver resection were determined during a weekly multidisciplinary meeting. Preoperatively the workup included blood tests, tumor markers, imaging modalities [computed tomography (CT), positron emission tomography CT (PET-CT) and magnetic resonance imaging (MRI)], and characterization of the liver metastases (number, location, size, and relation to intrahepatic vascular or biliary structures). All the patients were informed in detail about the procedure, including the risks and benefits, and written consent was obtained before surgery. All the HALS procedures were performed by the same surgical team under the direction of the same attending surgeon (R.H.). Open liver resection were performed by 3 HPB surgeons.

\section{Surgical Technique}

In brief, in the open group, the J-shaped subcostal incision was used, followed by mobilization of the liver and subsequent liver resection as standard.

In the HALS group, the procedure was performed as described earlier by Sadot et al. (19). Three trocars (two $12-\mathrm{mm}$ and one $5-\mathrm{mm}$ ) were inserted in the upper midline abdomen, and a hand-assisted device (GelPort, Applied Medical, CA, USA) was placed in the right abdominal horizontal incision $(7-8 \mathrm{~cm})$. The pneumoperitoneum was generated with $\mathrm{CO}_{2}$ at a pressure of $12-$ $15 \mathrm{mmHg}$, and visual exploration of the abdominal cavity was conducted with a $30^{\circ}$ laparoscope. Intra-abdominal sonography of the liver was performed in order to plan the liver resection, followed by mobilization of the liver according to the location of the lesions. The liver resections were carried out using a 5-mm bipolar sealing device (LigaSure Dolphin tip; Valleylab, Boulder, CO, USA), Endo GIA ${ }^{\mathrm{TM}}$ staplers (vascular cartridge, Endo GIA ${ }^{\mathrm{TM}}$, Covidien, Norwalk, CT, USA), and the Cavitron Ultrasonic Surgical Aspirator (CUSA; Valleylab, Boulder, CO, USA). The specimen was then extracted through the handassisted device without a bag. The surgical field was irrigated and checked for bleeding or bile. Before completion of the operation, central venous and blood pressure were restored to normal parameters to confirm hemostasis. An abdominal Jackson-Pratt (JP) drain was usually placed through a 5-mm port site. The wounds were then closed in layers after deflation of the pneumoperitoneum. All specimens were sent fresh for pathologic examination to measure the surgical margins.

Blood loss was estimated using the volume of blood aspirated from the abdominal cavity during the procedure. Operative time was defined as the time elapsed from the skin incision until closure. Postoperative hospital stay was defined as the number of hospitalized days from the first day after operation until the day of discharge. From the pathological report, we collected the data on the number of metastases, the largest tumor's diameter, and the narrowest margin distance for each patient. R0 was defined as no cancer cells seen microscopically at the resection margin. Complications were classified according to the Clavien-Dindo grading system. Clinical risk score (CRS) was stratified into two 
groups: the first group was composed of patients with a low CRS (0-2 points), and the second group was composed of patients with a high CRS (3-5 points).

During the follow-up period, the patients were followed by our multidisciplinary team during the first month, every 4 months in the first 2 years, and then twice a year. Followups included clinical examinations, blood work-up including carcinoembryonic antigen (CEA), and spiral CT of the chestabdomen or PET-CT.

\section{Statistical Analysis}

Data were analyzed using the Statistical Product and Service Solutions 25.0 package for Macintosh (SPSS Inc., Chicago, IL, USA). Results were presented as means and standard deviations. The overall survival and disease-free survival were determined using the Kaplan Meier method. Comparisons were made using the c2 test or one-way ANOVA for categorical or continuous variables, respectively, and a $p$-value $<0.05$ was considered as statistically significant.

\section{RESULTS}

\section{Study Population}

During the study period, 187 patients with mCRC located in the posterior-superior liver segments were identified; 78 of them underwent HALS and the remaining 109 patients underwent OLR. The characteristics of the patients including their demographic and pre-operative clinical data are shown in Table 1. Both patient groups had a comparable mean age (OLR $66 \pm 11$ years vs. HALS $64 \pm 12$ years; $p=0.64$ ) and a comparable division of the sexes (OLR 58\% males vs. HALS $47 \%$; $p=0.26$ ).

The anatomical distribution of the primary colorectal tumors did not show statistically significant differences $(p=0.95)$ between the two groups; most of the tumors in both groups were located in the right-side colon (43\%). Another one-fifth of the patients presented with rectal cancer (laparoscopic group 19\% vs. open surgery group $21 \%$ ).

When considering liver metastases, the patient groups had comparable pathology. Specifically, there were no statistically significant differences in the median size of the largest liver metastases from the pathological specimens (OLR $24.5 \mathrm{~mm}$ vs. HALS $20 \mathrm{~mm} ; p=0.19$ ); both patient groups had a median number of 1 metastasis ( $p=0.93$ ); and both groups $50 \%$ of the patients had more than one metastasis. Moreover, there was no significant group difference in the proportion of patients with a high CRS score (OLR 16\% vs. HALS 18\%; $p=0.78$ ). Lastly, a comparable proportion of patients in each group received neoadjuvant chemotherapy [OLR 69 (63\%) patients vs. HALS 55 (72\%) patients; $p=0.24$ ].

\section{Clinicopathologic Characteristics of the Patients' Liver Lesions}

The patients' laparoscopy or open surgery liver resection procedures of mCRC liver metastases are detailed in Table 2. Both patient groups underwent non-anatomical parenchymal sparing liver resections. There was no difference in the anatomical distribution of the liver metastases between the OLR
TABLE 1 | Baseline demographical, liver and colorectal characteristics.

\begin{tabular}{|c|c|c|c|}
\hline & $\begin{array}{l}\text { Laparoscopic } \\
\quad(n=78)\end{array}$ & $\begin{array}{c}\text { Open } \\
(n=109)\end{array}$ & $p$-value \\
\hline Age (years) mean & $64 \pm 12$ & $66 \pm 11$ & 0.64 \\
\hline Gender & & & 0.26 \\
\hline Male & $37(47.4 \%)$ & 57 (58\%) & \\
\hline Female & 41 (52.4\%) & 52 (42\%) & \\
\hline Primary tumor location & & & 0.81 \\
\hline Right colon & 25 (32\%) & $34(31 \%)$ & \\
\hline Left colon & 26 (33\%) & 38 (35\%) & \\
\hline Rectum & $26(33 \%)$ & $34(31 \%)$ & \\
\hline \multicolumn{4}{|l|}{ Liver tumor } \\
\hline Median size of largest metastases (mm) & $20(13: 32)$ & $24.5(15 ; 35)$ & 0.19 \\
\hline Number of metastases & & & 0.9 \\
\hline 1 & $40(51 \%)$ & 54 (52\%) & \\
\hline 2 & 15 (19\%) & $26(25 \%)$ & \\
\hline$>3$ & $23(30 \%)$ & $24(23 \%)$ & \\
\hline Number (median) & $1(1 ; 2)$ & $1(1 ; 2)$ & 0.93 \\
\hline Synchronous & $40(51 \%)$ & $49(45 \%)$ & 0.37 \\
\hline Metachronous & $38(49 \%)$ & & \\
\hline Clinical risk factor & & & 0.78 \\
\hline Low & 67 (86\%) & 92 (84\%) & \\
\hline High & $11(14 \%)$ & 17 (16\%) & \\
\hline Neoadjuvant therapy & 56 (72\%) & 69 (63\%) & 0.24 \\
\hline
\end{tabular}

and HALS groups. However, 33 (42\%) patients in the HALS group and $39(36 \%)$ in the OLR group had multiple liver resections in the postero-superior segments.

\section{Perioperative Outcome}

Perioperative outcomes are shown in Table 2. The total operation time was comparable between the two patient groups; $266 \pm$ $132 \mathrm{~min}$ in the OLR vs. $251 \pm 148 \mathrm{~min}$ in the HALS group ( $p=$ 0.49). The transfusion rate was also comparable; OLR 35 (32\%) patients vs. HALS 18 (23\%) patients; $p=0.11$. In the HALS group, conversion was required for two patients (3\%) due to bleeding during liver transection.

The length of hospital stay was significantly shorter in the HALS group (median 4 days) than in the OLR group (median 6 days); $p=0.003$. No death within 90 days after hepatectomy was observed in either group.

The overall postoperative morbidity rate was significantly lower in the HALS group compared to the OLR group (25 vs. $47 \%$; $p=0.003$ ). The OLR group also showed a significantly higher rate of major complications "Clavien Dindo III-IV" (25 vs. $9 \% ; p=0.006)$. Nine patients $(4.8 \%)$ had bile leek in both groups, the rate was $4.6 \%$ in OLR vs. $5.1 \%$ in LLR $(p=0.56)$. No patients need re-laparotomy due to bleeding. Finally, an R0 resection was achieved in 69 patients (89\%) in the HALS group compared to 88 patients $(81 \%)$ in the OLR group $(p=0.24)$, with a mean histological tumor-free margin of $7.2 \pm 5.8 \mathrm{~mm}$ vs. $6.4 \pm 6 \mathrm{~mm}$ in the HALS and OLR groups, respectively, $(p=0.44)$. 
TABLE 2 | Surgical and histological results.

\begin{tabular}{lccc}
\hline & $\begin{array}{c}\text { Laparoscopic } \\
(\boldsymbol{n}=\mathbf{7 8})\end{array}$ & $\begin{array}{c}\text { Open } \\
(\boldsymbol{n}=\mathbf{1 0 9 )}\end{array}$ & $\boldsymbol{p}$-value \\
\hline Type of liver resection & & & 0.17 \\
Segment 1 & $2(2.5 \%)$ & $2(2 \%)$ & \\
Segment 4A & $7(9 \%)$ & $19(17 \%)$ & \\
Segment 7 & $16(20.5 \%)$ & $27(25 \%)$ & \\
Segment 8 & $14(18 \%)$ & $11(10 \%)$ & \\
B/W Segment 7-8 & $6(8 \%)$ & $11(10 \%)$ & \\
Mix 7, 8, 4A & $33(42 \%)$ & $39(36 \%)$ & \\
Conversion & $2(3 \%)$ & & \\
Simultaneous colon resection & $9(12 \%)$ & $17(16 \%)$ & 0.52 \\
Operative Time & $251 \pm 148$ & $266 \pm 132$ & 0.49 \\
Blood Transfusion & $18(23 \%)$ & $35(32 \%)$ & 0.11 \\
30-day mortality & $0(0 \%)$ & $0(0 \%)$ & \\
Complications & $20(25 \%)$ & $51(47 \%)$ & 0.003 \\
$\quad$ Clavien Dindo I-II & $13(16 \%)$ & $24(22 \%)$ & \\
$\quad$ Clavien Dindo III-IV & $7(9 \%)$ & $27(25 \%)$ & 0.006 \\
Hospital stay (days) & $4(4 ; 6)$ & $6(4 ; 8)$ & 0.003 \\
Liver metastasis surgical margins & & & \\
R0 & $69(88.5 \%)$ & $88(81 \%)$ & 0.24 \\
Adjuvant chemotherapy & $58(74 \%)$ & $69(63 \%)$ & 0.34 \\
\hline
\end{tabular}

TABLE 3 | Short- and long-term outcomes.

\begin{tabular}{|c|c|c|c|}
\hline & $\begin{array}{l}\text { Laparoscopic } \\
\quad(n=78)\end{array}$ & $\begin{array}{c}\text { Open } \\
(n=109)\end{array}$ & $p$-value \\
\hline Median follow-up (months) & $40(23 ; 56)$ & $41(19 ; 92)$ & 0.32 \\
\hline \multicolumn{4}{|l|}{ Overall survival } \\
\hline Median (months) & 52 & 54 & 0.72 \\
\hline 12 (months) & $96 \%$ & $91 \%$ & \\
\hline 24 (months) & $84 \%$ & $76 \%$ & \\
\hline 36 (months) & $71 \%$ & $66 \%$ & \\
\hline 60 (months) & $47 \%$ & $45 \%$ & \\
\hline Liver recurrence & 43 (55\%) & 56 (51\%) & 0.65 \\
\hline Status & & & 0.11 \\
\hline Alive & 42 (54\%) & 63 (58\%) & \\
\hline Dead & $36(46 \%)$ & $46(42 \%)$ & \\
\hline
\end{tabular}

\section{Overall and Disease-Free Survival}

Survival analyses are shown in Table 3. The median follow-up period was similar between the OLR and HALS groups (41 vs. 40 months, $p=0.32$ ). The 5 -year disease free survival, overall survival rate was similar in both the OLR and HALS groups (36 vs. $22 \%, p=0.07$ and 0.45 vs. $47 \%, p=0.72$ respectively) (see Figure 1).

Liver disease recurrence occurred in 43 (55\%) patients in the HALS group and $56(51 \%)$ patients in the OLR group $(p=0.65)$.

\section{DISCUSSION}

The findings of this study demonstrate that the laparoscopic approach is safe, feasible and preferable for resection of mCRC located in the postero-superior segments of the liver. This was shown by a significantly shorter hospital stay and lower complication rate in the laparoscopic group compared to the open surgery group. Liver metastases recurrence and 5-year survival were similar in both patient groups.

Surgical resection remains the only effective treatment for mCRC to the liver. In addition, in the last decade there has been a shift toward parenchymal-sparing surgery which has become the gold standard for the treatment of colorectal liver metastases. The advantages of this approach are in preserving healthy remnant liver parenchyma and maintaining the liver vasculature anatomy. Accordingly, multiple liver resections and repeated hepatectomies can be carried out if needed. Parenchymal-sparing surgery has subsequently decreased the rate of morbidity and mortality and repeated hepatectomies when needed are associated with improved longterm survival.

The three consensus guidelines [Louisville (13), Morioka (7) and Southampton (14)] on laparoscopic liver resections estimate that pure laparoscopic liver resection, HALS, and the hybrid technique appear to be equivalent and are just a matter of surgeon preference. It has also been suggested that the HALS technique may be used to manage intraoperative difficulties and act as a bridge from learning open procedures to laparoscopy surgeries.

Historically, LLR was advocated for liver lesions located in the anterolateral segments, while the open approach was preferred for posterosuperior lesions. With increasing experience, LLR of more challenging lesions in the posterosuperior segments has become possible (20). However, in the Southampton 2018 guidelines there were warnings and limitations for formal laparoscopic hemi-hepatectomy and for lesions in the postero-superior segments (14). These warnings were because of concerns regarding the limited visualization of the posterior surface of the liver, the risks of bleeding since the postero-superior segments are adjacent to the major liver vasculature, and the difficulty to control bleeding.

In conventional open liver surgery for $\mathrm{mCRC}$, large incisions are usually required. Whereas, the benefits of liver minimalinvasive surgery are mainly related to smaller incisions with less operative trauma, reduced levels of postoperative pain, and faster gain of functional recovery (20). These benefits are the main reason for shortening the time to resume the adjuvant chemotherapy.

In our experience, HALS has been used during the learning curve as a bridge to master the pure LLR. However, it has now been abandoned for minor hepatic resections while still being valuable for major resections and tumors located in the postero-superior segments. In addition, only after we gained experience in HALS-liver resections of "laparoscopic segments" and were comfortable with the technique, did we then begin to perform HALS-resections of $\mathrm{mCRC}$ in the postero-superior segments. The main advantages of HALS over LLS, especially in the parenchymal preserving resection of lesions in the postersuperior segments, are: (i) the faster mobilization of the liver; (ii) the better exposure of difficult metastases locations; (iii) the use of tactile sensation for the detection of subcapsular lesions or superficial small diminished lesions after neoadjuvant 


\section{A}

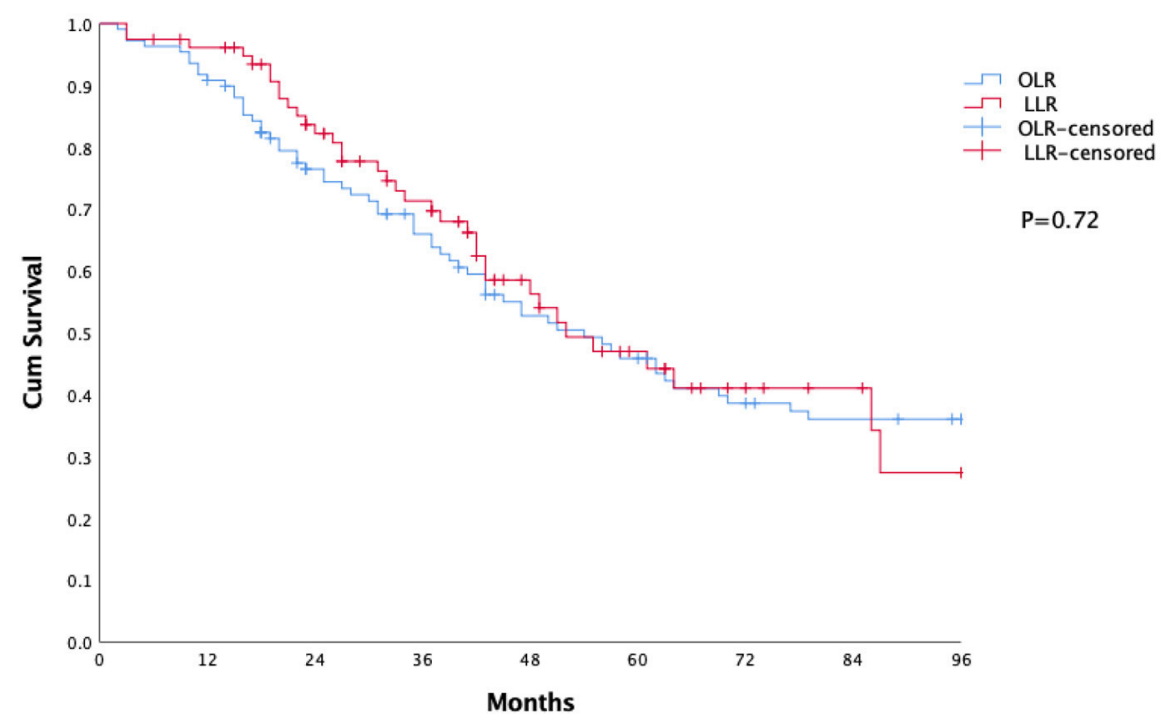

B

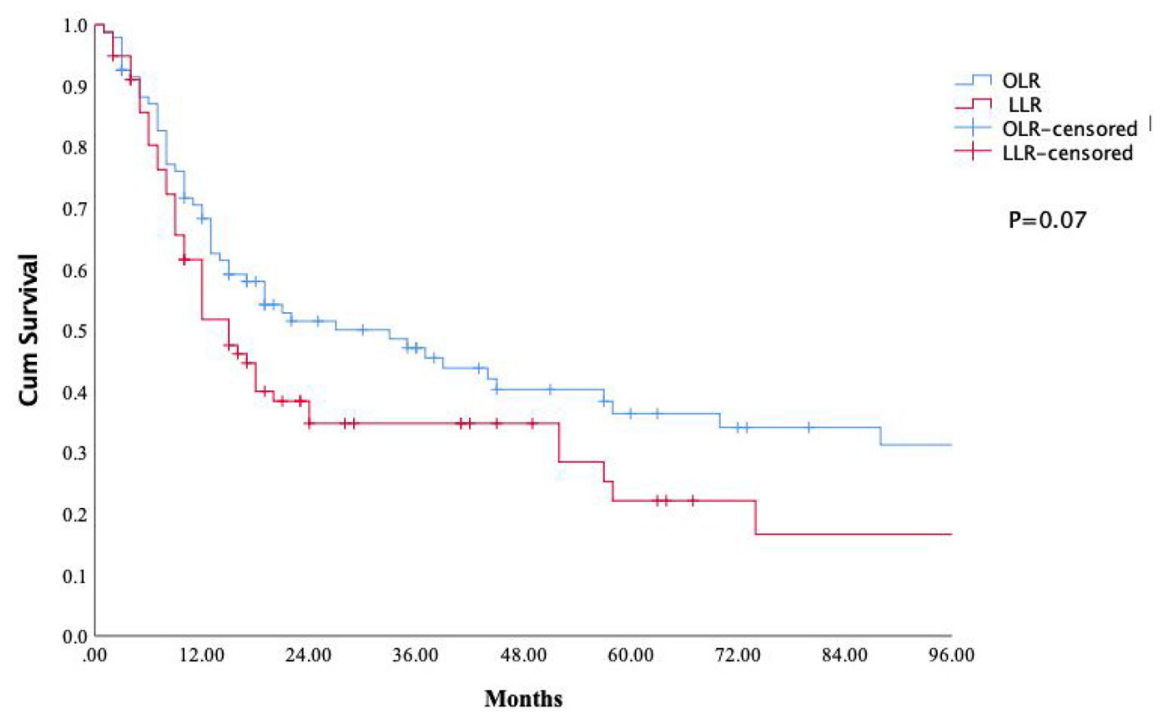

FIGURE 1 | Kaplan-Mayer curve survival. (A): Overall survival. (B): Recurrence free survival. OLR, Open liver resection; LLR, laparoscopic liver resection.

chemotherapy; (iv) the better identification of safe resection margins; and ( $\mathrm{v}$ ) the possibility to achieve faster hemostasis of intra-operative bleeding through manual compression. It is worth noting that in minimal invasive liver resections, a 6$8 \mathrm{~cm}$ incision is needed to retrieve the resected liver. In pure laparoscopy, a Pfannenstiel incision is made; whereas in HALS, a transverse incision in the upper right abdomen is required but the operative trauma remains significantly reduced compering to OLR. Indeed, Wabitsch et al. (21) reported no significant differences in HALS vs. LLR at operation time, postoperative complications, microscopic surgical margin involvement (R1) rate and general hospitalization time, but they did recommend the implementation of HALS before LLR in the posterosuperior segments. 
This study's findings showed that despite the technical difficulties of HALS-LLR for patients with postero-superior lesions, there were no significant differences compared to patients undergoing OLR in short-term outcomes, including global operative time and blood transfusion rates. However, there was a significant advantage of the HALS in terms of fewer total and major complications and shorter hospital stays. These results can be partly explained by the fact that LLR for posterosuperior segments were performed in our unit at a later stage of the implantation of the minimally invasive surgery (MIS) liver program. Notably, our findings are aligned with the results of a subgroup analysis of tumors in the posterosuperior segments from the first randomized controlled trial, the OSLO-COMET, that compared the outcomes of laparoscopic and open parenchymal-sparing liver resections for mCRC (22). Our findings are also similar to the results of a meta-analysis of 11 studies to compare the outcomes of OLR vs. LLR for mCRC and primary liver tumors in the postero-superior segments (21). This meta-analysis found no group differences in the need for blood transfusions and mortality, but the LLR group had a lower risk of total and major complications and a shorter hospital stay compared to the OLR group. Several additional studies have also reported the advantage of LLR compared to open surgery in terms of lower rates of total and major complications (23-33).

One of the major concerns in MIS liver resection is oncological outcome, especially the achievement of adequate free surgical margins. We found that using the HALS combined with meticulous laparoscopic intraoperative ultrasonography did not compromise the early oncological outcomes, and the rate of R0 margin was not statistically different between the OLR and HALS groups. This is in line with the results reported in the OSLO-COMET study (22) and in a meta-analysis conducted by Hajibandeh et al. (34).

Notably, the safety and feasibility of the HALS did not compromise long-term outcomes. Furthermore, there were no significant differences between the OLR and LLR patient groups in their 3 and 5-year overall survival and in the rate of liver recurrence. This is again in line with the results reported in the OSLO-COMET study (22) and in the Hajibandeh et al. (34) meta-analysis.

\section{REFERENCES}

1. Cleary SP. Minimally invasive liver surgery: has it achieved the standard of care? Ann Surg Oncol. (2018) 25:1105-7. doi: 10.1245/s10434-018-6380-2

2. Gagner M, Rogula $\mathrm{T}$, Selzer D. Laparoscopic liver resection: benefits and controversies. Surg Clin North Am. (2004) 84:451-62. doi: 10.1016/j.suc.2003.11.002

3. Cherqui D, Husson E, Hammoud R, Malassagne B, Stephan F, Benesaid $\mathrm{S}$, et al. Laparoscopic liver resections; a feasibility study in 30 patients. Ann Surg. (2000) 232:753-62. doi: 10.1097/00000658-20001200000004

4. Hibi T, Cherqui D, Geller DA, Itano O, Kitagawa Y, Wakabayashi G. Expanding indications and regional diversity in laparoscopic liver resection unveiled by the international survey on technical aspects of laparoscopic liver resection (INSTALL) study. Surg Endosc. (2016) 30:297583. doi: 10.1007/s00464-015-4586-y
There are a few limitations to the study. These include the retrospective data analysis and selection bias. In addition, all the LLR surgeries were performed by one hepatobiliary surgeon, while all the OLR operations were performed by three hepatobiliary surgeons. This creates some heterogenicity between the techniques employed for the parenchymal transections including the use of different devices.

\section{CONCLUSIONS}

HALS for CRLM in the postero-superior segments was associated with fewer total and major complications, a shorter hospital stay and similar oncological outcomes compared to open liver resection.

\section{DATA AVAILABILITY STATEMENT}

The raw data supporting the conclusions of this article will be made available by the authors, without undue reservation.

\section{ETHICS STATEMENT}

The studies involving human participants were reviewed and approved by Carmel Medical Canter and Rabin Medical Center. Written informed consent for participation was not required for this study in accordance with the national legislation and the institutional requirements.

\section{AUTHOR CONTRIBUTIONS}

OA-Z, MS, NG, and RH contributed to conception and design of the study. OA-Z, MS, and YB organized the database. AM and NG performed the statistical analysis. OA-Z wrote the first draft of the manuscript. All authors contributed to the article and approved the submitted version.

\section{ACKNOWLEDGMENTS}

The authors thank Dr. Ruth Moont for reviewing and editing the manuscript.

5. Ciria R, Cherqui D, Geller DA, Briceno J, Wakabayashi G. Comparative shortterm benefits of laparoscopic liver resection: 9000 cases and climbing. Ann Surg. (2016) 263:761-77. doi: 10.1097/SLA.0000000000001413

6. He J, Amini N, Spolverato G, Hirose K, Makary M, Wolfgang CL, et al. National trends with a laparoscopic liver resection: results from a populationbased analysis. HPB. (2015) 17:919-26. doi: 10.1111/hpb.12469

7. Wakabayashi G, Cherqui D, Geller DA, Buell JF, Kaneko H, Han HS, et al. Recommendations for laparoscopic liver resection: a report from the second international consensus conference held in Morioka. Ann Surg. (2015) 261:619-29. doi: 10.1097/SLA.0000000000001184

8. Benzing C, Krenzien F, Gohlke D, Andreou A, Haber P, Wabitsch S, et al. Health-related quality of life after laparoscopic liver resection. J Minim Access Surg. (2017). doi: 10.4103/jmas.JMAS_137_17. [Epub ahead of print].

9. Beppu T, Wakabayashi G, Hasegawa K, Gotohda N, Mizuguchi T, Takahashi $\mathrm{Y}$, et al. Long-term and perioperative outcomes of laparoscopic versus open liver resection for colorectal liver metastases with propensity score matching: 
a multi-institutional Japanese study. J Hepatobiliary Pancreat Sci. (2015) 22:711-20. doi: 10.1002/jhbp.261

10. Allard MA, Cunha AS, Gayet B, Adam R, Goere D, Bachellier P, et al. Early and longterm oncological outcomes after laparoscopic resection for colorectal liver metastases: a propensity score-based analysis. Ann Surg. (2015) 262:794-802. doi: 10.1097/SLA.0000000000001475

11. Hasegawa Y, Nitta H, Sasaki A, Takahara T, Itabashi H, Katagiri H, et al. Longterm outcomes of laparoscopic versus open liver resection for liver metastases from colorectal cancer: a comparative analysis of 168 consecutive cases at a single center. Surgery. (2015) 157:1065-72. doi: 10.1016/j.surg.2015.01.017

12. Cipriani F, Rawashdeh M, Stanton L, Armstrong T, Takhar A, Pearce NW, et al. Propensity score-based analysis of outcomes of laparoscopic versus open liver resection for colorectal metastases. Br J Surg. (2016) 103:1504-12. doi: 10.1002/bjs.10211

13. Buell JF, Cherqui D, Geller DA, O'Rourke N, Iannitti D, Dagher I, et al. World consensus conference on laparoscopic surgery. The international position on laparoscopic liver surgery: The Louisville statement 2008. Ann Surg. (2009) 250:825-30. doi: 10.1097/SLA.0b013e3181b3b2d8

14. Abu Hilal M, Aldrighetti L, Dagher I, Edwin B, Troisi RI, Alikhanov $\mathrm{R}$, et al. The southampton consensus guidelines for laparoscopic liver surgery. From indication to implantation. Ann Surg. (2018) 268:11-18. doi: 10.1097/SLA.0000000000002524

15. Ban D, Tanabe M, Ito H, Otsuka Y, Nitta H, Abe Y, et al. A novel difficulty scoring system for laparoscopic liver resection. J Hepatobiliary Pancreat Sci. (2014) 21:745-53. doi: 10.1002/jhbp.166

16. Ogiso S, Nomi T, Araki K, Conrad C, Hatano E, Uemoto S, et al. Laparoscopyspecific surgical concepts for hepatectomy based on the laparoscopic caudal view: a key to reboot surgeons' minds. Ann Surg Oncol. (2015) 22(Suppl. 3):S327-33. doi: 10.1245/s10434-015-4661-6

17. Lee W, Han HS, Yoon YS, Cho JY, Choi Y, Shin HK. Role of intercostal trocars on laparoscopic liver resection for tumors in segments 7 and 8. J Hepatobiliary Pancreat Sci. (2014) 21:E65-8. doi: 10.1002/jhbp.123

18. Hasegawa Y, Koffron AJ, Buell JF, Wakabayashi G. Approaches to laparoscopic liver resection: a meta-analysis of the role of hand-assisted laparoscopic surgery and the hybrid technique. J Hepatobiliary Pancreat Sci. (2015) 22:33541. doi: 10.1002/jhbp. 214

19. Sadot E, Goldberg N, Damoni E, Aranovich D, Kashtan H, Batterman A, et al. Laparoscopic hand-assisted liver resection for tumours in the left lateral section. J Minim Access Surg. (2020) 16:35-40. doi: 10.4103/jmas.JMAS_148_18

20. Fretland ÅA, Dagenborg VJ, Bjørnelv GMW, Kazaryan AM, Kristiansen R, Fagerland MW, et al. Laparoscopic versus open resection for colorectal liver metastases: the OSLO-COMET randomized controlled trial. Ann Surg. (2018) 267:199-207. doi: 10.1097/SLA.0000000000002353

21. Wabitsch S, Schöning W, Kästner A, Haber PK, Benzing C, Krenzien F, et al. A propensity-matched study of full laparoscopic versus handassisted minimal-invasive liver surgery. Surg Endosc. (2021) 35:2021-8. doi: 10.1007/s00464-020-07597-2

22. Aghayan DL, Fretland ÅA, Kazaryan AM, Sahakyan MA, Dagenborg VJ, Bjørnbeth BA, et al. Laparoscopic versus open liver resection in the posterosuperior segments: a sub-group analysis from the OSLO-COMET randomized controlled trial. HPB. (2019) 21:1485-90. doi: 10.1016/j.hpb.2019.03.358

23. Del Pino S, Fischer L, Nashan B, Jun L. Reduced opioid demand and fewer pulmonary complications after laparoscopic liver resection in the posterior segments. Dig Surg. (2020) 37:129-34. doi: 10.1159/000497453

24. Morikawa $T$, Ishida $M$, Takadate $T$, Aoki $T$, Ohtsuka H, Mizuma M, et al. Laparoscopic partial liver resection improves the short-term outcomes compared to open surgery for liver tumors in the posterosuperior segments. Surg Today. (2019) 49:214-23. doi: 10.1007/s00595-018-1719-7

25. Okuno M, Goumard C, Mizuno T, Omichi K, Tzeng CD, Chun YS, et al. Operative and short-term oncologic outcomes of laparoscopic versus open liver resection for colorectal liver metastases located in the posterosuperior liver: a propensity score matching analysis. Surg Endosc. (2018) 32:1776-86. doi: 10.1007/s00464-017-5861-x

26. Rhu J, Kim SJ, Choi GS, Kim JM, Joh JW, Kwon CHD. Laparoscopic versus open right posterior sectionectomy for hepatocellular carcinoma in a highvolume center: a propensity score matched analysis. World J Surg. (2018) 42:2930-7. doi: 10.1007/s00268-018-4531-z

27. Scuderi V, Barkhatov L, Montalti R, Ratti F, Cipriani F, Pardo F, et al. Outcome after laparoscopic and open resections of posterosuperior segments of the liver. Br J Surg. (2017) 104:751-9. doi: 10.1002/bjs.10489

28. D’Hondt M, Tamby E, Boscart I, Tucotte S, Parmentier I, Pottel H, et al. Laparoscopic versus open parenchymal preserving liver resections in the posterosuperior segments: a case-matched study. Surg Endosc. (2018) 32:1478-85. doi: 10.1007/s00464-017-5835-Z

29. Guro H, Cho JY, Han HS, Yoon YS, Choi Y, Jang JS, et al. Laparoscopic liver resection of hepatocellular carcinoma located in segments 7 or 8. Surg Endosc. (2018) 32:872-8. doi: 10.1007/s00464-017-5756-x

30. Tarantino G, Magistri P, Serra V, Berardi G, Assirati G, Ballarin R, et al. Laparoscopic liver resection of right posterior segments for hepatocellular carcinoma on cirrhosis. J Laparoendosc Adv Surg Tech A. (2017) 27:559-63. doi: 10.1089/lap.2016.0506

31. Xiao L, Xiang LJ, Li JW, Chen J, Fan YD, Zheng SG. Laparoscopic versus open liver resection for hepatocellular carcinoma in posterosuperior segments. Surg Endosc. (2015) 29:2994-3001. doi: 10.1007/s00464-015-4214-x

32. Cho JY, Han HS, Yoon YS, Choi Y, Lee W. Outcomes of laparoscopic right posterior sectionectomy in patients with hepatocellular carcinoma in the era of laparoscopic surgery. Surgery. (2015) 158:135-41. doi: 10.1016/j.surg.2015.02.007

33. InagakiH, Kurokawa $\mathrm{T}$, Yokoyama $\mathrm{T}$, Konish $\mathrm{T}$, Kikuchi M, Yokoyama $\mathrm{Y}$, et al. Hand-assisted laparoscopic hepatectomy for tumors located in posterior segment. Hepatogastroenterology. (2008) 55:1695-8.

34. Hajibandeh S, Hajibandeh S, Dave M, Tarazi M, Satyadas T. Laparoscopic versus open liver resection for tumors in the posterosuperior segments: a systematic review and meta-analysis. Surg Laparosc Endosc Percutan Tech. (2020) 30:93-105. doi: 10.1097/SLE.0000000000000746

Conflict of Interest: The authors declare that the research was conducted in the absence of any commercial or financial relationships that could be construed as a potential conflict of interest.

Publisher's Note: All claims expressed in this article are solely those of the authors and do not necessarily represent those of their affiliated organizations, or those of the publisher, the editors and the reviewers. Any product that may be evaluated in this article, or claim that may be made by its manufacturer, is not guaranteed or endorsed by the publisher.

Copyright (c) 2021 Abu-Zaydeh, Sawaied, Berger, Mahamid, Goldberg, Sadot and Haddad. This is an open-access article distributed under the terms of the Creative Commons Attribution License (CC BY). The use, distribution or reproduction in other forums is permitted, provided the original author(s) and the copyright owner(s) are credited and that the original publication in this journal is cited, in accordance with accepted academic practice. No use, distribution or reproduction is permitted which does not comply with these terms. 